\title{
Estudo etnobotânico de plantas medicinais na comunidade de Santa Rita, Ituiutaba - MG
}

\author{
Glaucieli Siqueira Parreira Alves * \\ Juliana Aparecida Povh \\ Universidade Federal de Uberlândia, Faculdade de Ciências Integradas do Pontal, Rua 20, 1600, \\ Bairro Tupã, CEP: 38304-402, Ituiutaba, Minas Gerais - Brasil \\ *Autor para correspondência \\ glauci.parreira@hotmail.com
}

Submetido em 13/11/2012

Aceito para publicação em 03/07/2013

\section{Resumo}

O objetivo deste artigo foi inventariar as plantas utilizadas na medicina popular pelos membros da comunidade rural de Santa Rita, no município de Ituiutaba - MG. A avaliação foi realizada por meio de entrevistas, com um questionário semiestruturado, e posterior coleta das plantas indicadas pelos informantes. Foram realizadas 47 entrevistas e 127 espécies foram listadas, pertencentes a 55 famílias de Angiospermas. Para obtenção dos dados quantitativos foi calculada a porcentagem de Concordância de Usos Principais (CUP) de cada espécie; para identificar as indicações terapêuticas de maior importância, utilizou-se o Fator de Consenso dos Informantes (FCI). A CUP demonstrou que 5,5\% das plantas citadas são amplamente utilizadas pela comunidade. As famílias botânicas predominantes foram Lamiaceae e Asteraceae, com 14 e 13 registros, respectivamente. A indicação de uso predominante envolveu, principalmente, afecções relacionadas a distúrbio emocional, conforme indicado pelo FCI. Salienta-se que $60,7 \%$ das plantas citadas neste artigo são espécies exóticas; desse modo, se faz necessário mais estudos para catalogar o conhecimento sobre as plantas medicinais nativas dessa região.

Palavras-chave: Cerrado; Etnobotânica; Medicina popular

\section{Abstract}

Ethnobotanical study of medicinal plants in the community of Santa Rita, Ituiutaba - Minas Gerais, Brazil. This paper aimed to inventory the plants used in popular medicine by members of the rural community of Santa Rita, in the town of Ituiutaba, Minas Gerais, Brazil. The evaluation was carried out through interviews, with a semi-structured questionnaire and subsequent collection of the plants indicated by informants. One conducted 47 interviews and 127 species were listed, belonging to 55 Angiosperm families. For obtaining the quantitative data, one calculated the percentage of the Main Use Concordance (cMUC) of each species; for identifying the therapeutic indications with greater importance, one used the Informant Consensus Factor (ICF). The cMUC showed that $5.5 \%$ of the plants mentioned are widely used by the community. The predominant botanical families registered were Lamiaceae and Asteraceae, with 14 and 13 records, respectively. The indication of predominant use mainly involved illnesses related to an emotional disorder, as indicated by the ICF. One emphasizes that $60.7 \%$ of the plants mentioned in this paper are exotic species; thus, there's a need for further studies in order to catalogue knowledge on the medicinal plants which are native to this region.

Key words: Cerrado; Ethnobotany; Popular medicine 


\section{Introdução}

O uso das plantas como medicamento terapêutico para diversas doenças representou, durante séculos, a única alternativa ao homem (HOSTETTMANN et al., 2003). No Brasil, a medicina popular apresenta aspectos peculiares, pois não está limitada apenas a comunidades tradicionais, como os grupos indígenas ou quilombolas, mas é praticada também por moradores da zona rural e outras comunidades que habitam os biomas brasileiros (DI STASI, 2007a).

Nesse sentido, o conhecimento empírico de muitas comunidades rurais sobre a utilização de recursos naturais tem despertado grande interesse acadêmico por conservarem valiosos conhecimentos e espécies potenciais (CALIXTO; RIBEIRO, 2004).

Este tipo de sabedoria popular é validada pelos estudos envolvendo áreas multidisciplinares como a fitoquímica e a farmacologia, que tem buscado evidências nos estudos etnobotânicos sobre novas substâncias vegetais que possam ser aplicadas nas áreas médica e industrial (ALBUQUERQUE, 2005; MACIEL et al., 2002).

A abordagem etnobotânica, entre outros aspectos, permite investigar e analisar o uso das plantas com finalidades terapêuticas de determinado grupo populacional, bem como entender a história e a relação do homem com essas plantas (ALBUQUERQUE, 2005; ALBUQUERQUE; HANAZAKI, 2006). Do mesmo modo, é importante ressaltar que a investigação etnobotânica também contribui para o desenvolvimento de novas formas de exploração dos ecossistemas, beneficiando recursos que promovam o uso e manejo sustentáveis se contrapondo às formas de devastação atual (ALBUQUERQUE, 1999).

Exemplo desta devastação é a situação do bioma Cerrado, que se encontra entre os 17 ecossistemas mais degradados do mundo, sendo por isso, listado como hotspot de biodiversidade (MARONI et al., 2006). Cerca de $80 \%$ do cerrado já foi modificado por ações antrópicas, restando apenas 19\% de áreas fragmentadas de vegetação original e somente $1 \%$ disso encontra-se em Unidades de Conservação (MARONI et al., 2006).

O Cerrado brasileiro ocupa cerca de 2 milhões de $\mathrm{km}^{2}$ de área, o que representa quase $20 \%$ do território nacional. É o segundo maior bioma brasileiro e se destaca por apresentar grande biodiversidade, com cerca de $22 \%$ das espécies biológicas registradas (ALVES et al., 2008; MARONI et al., 2006).

Neste contexto, há necessidade de estudos etnobotânicos em comunidades rurais deste bioma visando catalogar as espécies vegetais utilizadas na medicina popular resgatando o conhecimento e a relação que estas populações possuem com as plantas, o que pode contribuir para a conservação do cerrado e seu uso sustentável (DI STASI, 2007b). Além disso, estudos etnobotânicos podem contribuir para que outras áreas de estudo tenham subsídio para pesquisa, como a área farmacêutica (ALBUQUERQUE, 2005), que possui grande interesse pelos produtos de origem vegetal.

Na região do Triângulo Mineiro há o registro da realização de poucos trabalhos etnobotânicos, sendo assim, é importante ressaltar a carência de pesquisas voltadas ao estudo das plantas medicinais, especialmente com foco na biodiversidade do Cerrado.

O presente estudo objetivou catalogar as plantas utilizadas pelos membros da comunidade rural de Santa Rita, empregadas como medicinais, visando obter mais informações sobre espécies do cerrado utilizadas para fins terapêuticos.

\section{Material e Métodos}

\section{Área de estudo}

A comunidade de Santa Rita localiza-se no município de Ituiutaba, situado no pontal do Triângulo Mineiro, planalto central do Brasil, entre as coordenadas $18^{\circ} 58^{\prime} 08^{\prime}$ 'S e $49^{\circ} 27^{\prime} 54^{\prime \prime} \mathrm{W}$. Possui área territorial de $2.694 \mathrm{~km}^{2}$, apresentando altitude máxima de $769 \mathrm{~m} \mathrm{e}$ mínima $550 \mathrm{~m}$. O clima é classificado como quente úmido, AW na classificação de Köppen, com estação chuvosa bem definida no período de outubro a abril, e um período seco de maio a setembro. A precipitação anual média é de $1.470 \mathrm{~mm}$. As temperaturas médias anuais encontram-se entre $14^{\circ} \mathrm{C}$ a mínima (junho) e $31^{\circ} \mathrm{C}$ máxima (dezembro). A umidade relativa do ar apresenta índice médio anual aproximado de 70\% (PREFEITURA MUNICIPAL DE ITUIUTABA, 2012). 
A paisagem vegetacional predominante é o Cerrado, característico do geo-sistema dos planaltos aplainados do Brasil Central. A região compreende vários tipos fisionômicos de Cerrados como Mata de galeria ou ciliar, Mata mesofítica ou Subcaducifólica de encosta, Mata de várzea, Cerradão, Cerrado strico-sensu, Campo sujo ou Cerradinho, Campo limpo ou Hidromórfico e Vereda (PREFEITURA MUNICIPAL DE ITUIUTABA, 2012).

A Comunidade de Santa Rita é uma associação de moradores da região, fundada em agosto de 1986, sendo atualmente composta por 63 associados. Os associados são pequenos ${ }^{1}$ e grandes ${ }^{2}$ produtores rurais que desenvolvem diferentes atividades, desde criação de gado de corte e leiteiro, produção de queijo, rapadura, doces, hortaliças e frutas, além de alguns produtos artesanais. A referida associação é regida por um estatuto que tem por finalidade promover discussões que visam melhorias para a região; para tanto, são realizadas reuniões mensais na sede da comunidade, que visam à identificação dos problemas e soluções para os mesmos.

\section{Métodos}

Inicialmente, para obter o consentimento da comunidade, o trabalho foi apresentado aos associados em uma reunião, onde foram esclarecidos seus objetivos e procedimentos. Posteriormente, o trabalho foi submetido (protocolo registro: CEP/UFU 254/11) e aprovado (análise: CEP/UFU 842/11) pelo Comitê de Ética em Pesquisas com Seres Humanos - CEP/UFU, de acordo com a Resolução 196/96 do Conselho Nacional de Saúde.

A coleta dos dados etnobotânicos foi realizada de dezembro 2011 a março de 2012, por meio de um questionário semi-estruturado, adaptado de Berlin e Berlin (2005). As abordagens foram realizadas diretamente aos membros da comunidade em suas respectivas residências. Para concretizar a entrevista, os moradores que aceitaram participar da pesquisa, um total de 47 participantes teve que preencher o Termo de

1 Pequeno Produtor Rural é aquele que, detém posse de gleba rural não superior a 50 (cinquenta) hectares, explorando-a mediante o trabalho pessoal e de sua família [...] (BRASIL, 2006).

2 Grande Produtor rural aquele que possui gleba rural superior a 50 (cinquenta) hectares.
Consentimento Livre Esclarecido - TCLE, de acordo com o modelo elaborado pelo Comitê de Ética em Pesquisa com Seres Humanos - CEP/UFU.

Após as entrevistas, as plantas citadas foram localizadas e coletadas. Posteriormente este material foi herborizado e identificado, com auxilio de literatura especializada segundo APGII (LORENZI, 1998; LORENZI; MATOS, 2002; SOUZA; LORENZI, 2005; 2008) e acondicionado no Laboratório de Botânica da Faculdade de Ciências Integradas do Pontal Universidade Federal de Uberlândia.

Para cada planta citada elaborou-se um registro, contemplando: família, nome científico, nome vulgar, parte utilizada, indicação terapêutica, forma de preparo e categoria da planta, cultivada ou nativa (Tabela 1). Denominou-se planta cultivada as encontradas nos quintais, hortas e jardins das residências, e nativa, as plantas não cultivadas (espontâneas) ou pertencentes à vegetação do Cerrado. As categorias terapêuticas foram adaptadas de acordo com o CID-10, Classificação Estatística Internacional de Doenças e Problemas Relacionados à Saúde (BRASIL, 2008).

A partir dos dados obtidos, verificou-se a Importância Relativa das espécies citadas como medicinal, de acordo com a metodologia proposta por Amorozo e Gély (1988). Assim a Importância Relativa foi obtida pela porcentagem de Concordância quanto aos Usos Principais de cada espécie (CUP), usando o número de informantes referindo os usos principais vezes 100, dividido pelo total de informantes que citaram a espécie. O resultado encontrado foi multiplicado por um Fator de Correção (FC), correspondente ao número de informantes que citaram a espécie, dividido pelo número de informantes que citaram a espécie mais citada. A CUP corrigida então é dada pela fórmula:

$$
\text { CUPc }=\text { CUP } \times \text { FC, onde: }
$$

CUPc $=$ Porcentagem de concordância quanto aos usos principais de cada espécie corrigida

CUP $=$ Porcentagem de concordância quanto aos usos principais de cada espécie

$\mathrm{FC}=$ Fator de correção (número de informantes que citaram a espécie, dividido pelo número de informantes que citaram a espécie mais citada). 
Os valores de Concordância quanto aos Usos Principais Corrigidos para cada espécie (CUPc) estão no intervalo de 0 a 100, assim quanto maior for o valor obtido, maior é o número de citações para a espécie quanto a sua principal utilização (AMOROZO; GÉLY, 1988).

Para identificar a uniformidade das indicações terapêuticas de maior importância, utilizou-se o Fator de Consenso dos Informantes (FCI), técnica elaborada por Trotter e Logan (1986, apud Ragupathy et al., 2008), através da fórmula: $\mathrm{FCI}=$ nur-nt/nur-1, (nur = número de citações de uso em cada categoria; $\mathrm{nt}=$ número de espécies utilizadas na categoria.

\section{Resultados e Discussão}

Foram realizadas 47 entrevistas, sendo 50,6\% dos entrevistados do sexo feminino e $40,4 \%$ do sexo masculino, com intervalo de idades entre 24 e 88 anos. A faixa etária mais representativa compreendeu entre 60 e 69 anos, perfazendo um total de $23,45 \%$ dos entrevistados. Em seguida a faixa etária de $40-49$ anos, totalizou $21,27 \%$ dos informantes. Entre a faixa etária de 50 - 59 anos, houve 19,15\% entrevistados. Dentre os informantes da faixa etária 30 - 39 houve $14,89 \%$. As idades $70-79$ e $20-29$ tiveram $8,52 \%$ dos entrevistados respectivamente. A faixa etária de informantes mais velhos $(80-89)$ teve menor número de informantes 4,25\%. Quanto à escolaridade, a maioria dos participantes (89\%) não concluiu o Ensino Fundamental, apenas três terminaram o ensino médio e somente dois cursaram o Ensino Superior. De todos os informantes, apenas quatro moram na região há oito anos e o restante há mais de 35 anos.

As citações etnobotânicas compreenderam 127 espécies, distribuídas em 55 famílias (Tabela 1). As famílias botânicas mais representativas foram Lamiaceae (14 espécies), Asteraceae (13 espécies), Fabaceae (nove espécies), Rutaceae (sete espécies), Euphorbiaceae (cinco espécies), Cucurbitaceae, Poaceae e Myrtaceae (quatro espécies cada). As outras 46 famílias tiveram citações igual ou inferior a três espécies. Lamiaceae e Asteraceae também foram as famílias mais representativas encontradas nos trabalhos de Christo et al. (2006), Teixeira e Melo (2006) e Costa e Mayworm (2011). As famílias Fabaceae, Rutaceae, Euphorbiaceae, Cucurbitaceae, Poaceae e Myrtaceae também foram encontradas com maior representatividade nos estudos de Cunha e Bortolotto (2011) e Pasa (2011).

A maior representatividade da família Lamiaceae encontrada neste trabalho (Tabela 1) pode ser explicada por sua distribuição cosmopolita e grande importância terapêutica, evidenciada em estudos anteriores (DI STASI et al., 2002; PINTO et al., 2006). Ainda, de acordo com Judd et al. (2009), os membros desta família se destacam por serem ricos em óleos essenciais, o que atribui a estas espécies propriedades aromáticas e medicinais. Segundo Souza e Lorenzi (2005), grande parte das espécies da família Asteraceae são nativas, com ocorrência principalmente no cerrado, corroborando o dado encontrado neste estudo. Ainda, de acordo Di Stasi et al. (2002), esta família é uma fonte de plantas com interesse terapêutico, devido ao grande número de espécies usadas como medicamentos e incorporadas à medicina tradicional.

Neste estudo, assim como o mencionado em outros trabalhos, (AMOROZO; GÉLY, 1988; SILVA, 2002; CUNHA; BORTOLOTTO, 2011) as folhas foram a parte da planta mais citada, totalizando $44 \%$ da forma de utilização das espécies; em seguida a raiz, com $13 \%$ das espécies; o fruto e a casca com $9 \%$ das espécies. Os $25 \%$ restantes, foram referentes às folhas e flores; folhas e frutos; sementes; seiva e outros. A forma de preparo mais utilizada é o chá por decocção (53\%). Há também o chá por infusão (33\%), o macerado (7\%), vinho medicinal (6\%), tintura, suco, pó, banho, xarope e outros (1\%). Estas formas de preparo também foram encontradas por diversos autores (AMOROZO, 2002; PINTO et al., 2006; OLIVEIRA et al., 2010; COSTA; MAYWORM, 2011), entretanto a maior predominância verificada foi o chá por decocção e infusão.

A maioria das espécies citadas pelos entrevistados para uso medicinal é cultivada nas áreas manejadas $(60,7 \%)$. As demais espécies usadas são nativas do Cerrado, de ocorrência espontânea, sendo encontradas nos arredores das casas ou em áreas próximas. Este resultado difere do encontrado em trabalhos como os de Amorozo (2002), Oliveira et al. (2010) e Cunha e 
Bortolotto (2011), onde a maioria das espécies citadas foi descrita como nativa. Segundo Amorozo (2002), a menor frequência de uso de espécies nativas, bem como detrimento do conhecimento pode estar associado às formas de uso dos ambientes naturais que, devido às ações antrópicas, sofreram e vem sofrendo alterações. Esta afirmação se concretiza na fala dos entrevistados, quando declararam que algumas espécies estão desaparecendo devido às roçadas nas pastagens e pelos frequentes desmatamentos.

Outros fatores que ameaçam o repasse e a continuidade deste conhecimento são: a emigração do meio rural para as zonas urbanas e a ascensão da medicina moderna que, de certa forma, desvaloriza o conhecimento popular que deixa de ser passado de geração a geração (AMOROZO, 2002; PINTO at al., 2006; GIRALDI; HANAZAKI, 2010). De acordo com alguns entrevistados, seus filhos vão para a cidade em busca de trabalho e, com isso, diminuem a prática do uso das plantas medicinais e as substituem por medicamentos alopáticos. Desse modo, os mais jovens vão perdendo a prática da medicina popular e os aspectos da cultura local (OLIVEIRA et al., 2010). Vale ressaltar que neste trabalho $90 \%$ dos entrevistados, confirmaram obter o conhecimento sobre as plantas medicinais com seus familiares.

A maioria das plantas (42,5\%) apresentou baixos valores de CUPc, estando esses entre 0 e 24. 23,6\% delas apresentou valores intermediários de CUPc, entre 25 e 49 e somente $5,5 \%$ das plantas apresentaram valores de CUPc entre 50 e 100. O índice CUPc é referido à fidelidade quanto a principal utilização da espécie citada pelos informantes, podendo sugerir que as espécies com um índice de concordância relativamente alto podem ser promissoras para realização de estudos farmacológicos que possam corroborar a eficácia de suas propriedades terapêuticas (AMOROZO; GÉLY, 1988; VENDRUSCOLO; MENTZ, 2006).

As espécies que obtiveram o maior valor de CUPc foram: Cymbopogon citratus (DC) Stapf (capimcidreira), utilizada para gripe, expectorante e pressão alta; Croton antisiphiliticus Mart. (pé-de-perdiz), utilizada para infecções uterinas; Mentha pulegium L. (poejo), utilizada para gripes, expectorante e calmante; Mentha x villosa Huds (hortelã), utilizada para gripe; Plectranthus barbatus Andrews (boldo), utilizada para indigestão; Sambucus nigra L. (sabugueiro), utilizada para gripe; Stryphnodendron adstringens (Mart.) Coville (barbatimão), utilizada como cicatrizante e gastrite (Tabela 1). Valores alto de CUPc também foram observados por Pilla et al. (2006) para as espécies C.citratus, P. barbatus e os gêneros de Mentha sp.

O uso de $P$. barbatus para indigestão pode ser comprovado pelo valor máximo de concordância $($ CUPc $=100)$, corroborando a recomendação do Formulário de Fitoterápicos Farmacopeia Brasileira - FFFB (BRASIL, 2011), e o também encontrado por Pilla et al (2006) Vendruscolo e Mentz (2006).

As espécies Cymbopogon citratus, Sambucus nigra e Stryphnodendron adstringens também são espécies recomendadas como medicamento (BRASIL, 2011), porém a indicação terapêutica de $S$. nigra citada pelos informantes da comunidade difere da recomendada no FFFB. Portanto $S$. nigra pode ser indicada para estudos farmacológicos que visem validar as indicações terapêuticas aqui encontradas. $\mathrm{O}$ mesmo acontece com Croton antisiphiliticus, Mentha pulegium, Mentha $\mathrm{x}$ villosa espécies não indicadas no FFFB como medicamento nos Programas de Fitoterapia no SUS. Com exceção de $C$. antisiphiliticus e $S$. nigra todas as outras espécies com valores alto de CUPc possui informações fitoterápicas, fitoquímicas e farmacológicas apresentadas por Lorenzi e Matos (2002). Apenas para a espécie $C$. antisiphiliticus, não foram encontrados na literatura estudos farmacológicos comprovando suas indicações terapêuticas, mas vale ressaltar que esta espécie é nativa do cerrado e segundo os moradores nos últimos tempos, apresenta baixa ocorrência devido às frequentes roçadas das pastagens.

A Tabela 2 mostra as categorias terapêuticas e o resultado do Fator de Consenso dos Informantes (FCI). O FCI apresenta valor máximo de 1, quando ocorre total consenso entre os informantes (OLIVEIRA et al., 2010) quanto a utilização das espécies. Quanto maior o valor obtido mais alto é a representatividade do consenso dos informantes. 
TABELA 1: Espécies medicinais citadas pelos entrevistados da Comunidade de Santa Rita, Ituiutaba-MG. Parte utilizada (PU): Botões florais (bo-fl); Casca (c); Caule (ca); Cabelo de milho (ca-mi); Flores (fl); Folhas (fo); Frutos (fr); Raiz (r); Rizoma (ri); Seiva (sei); Semente (se); Concordância quanto aos usos principais (CUPc) Nativa (N) ou Cultivada (C).

\begin{tabular}{|c|c|c|c|c|c|c|}
\hline Família/espécie & Nome vulgar & PU & Indicação & Preparo & $\mathrm{N} / \mathrm{C}$ & CUPc \\
\hline $\begin{array}{l}\text { Alismataceae } \\
\text { Echinodorus grandiflorus Mitch. }\end{array}$ & chapéu-de-couro & fo & Afecções renais & Decocção & $\mathrm{N}$ & 38,70 \\
\hline $\begin{array}{l}\text { Amaranthaceae } \\
\text { Alternanthera dentata (Moench) Stuchlik }\end{array}$ & $\begin{array}{l}\text { terramicina, } \\
\text { novalgina }\end{array}$ & fo & $\begin{array}{l}\text { Gripe, infecções, febrífugo, } \\
\text { depurativo }\end{array}$ & Infusão & $\mathrm{C}$ & 30,70 \\
\hline $\begin{array}{l}\text { Anacardiaceae } \\
\text { Myracrodruon urundeuva Allemão }\end{array}$ & aroeira & c & Gastrite & Decocção & $\mathrm{N}$ & 7,69 \\
\hline Anacardium occidentale L. & caju & fo & Diarreia & Suco & $\mathrm{C}$ & 7,69 \\
\hline Mangifera indica $\mathrm{L}$. & manga & fo & Gripe & Decocção & $\mathrm{C}$ & 7,90 \\
\hline $\begin{array}{l}\text { Annonaceae } \\
\text { Annona muricata L. }\end{array}$ & graviola & fo, fr & Diabetes, câncer & Infusão & $\mathrm{C}$ & 7,60 \\
\hline $\begin{array}{l}\text { Apiaceae } \\
\text { Daucus carota } \mathrm{L} .\end{array}$ & cenoura & $\mathrm{r}$ & Antiemético & Suco & $\mathrm{C}$ & 7,69 \\
\hline Foeniculum vulgare Mill & $\begin{array}{l}\text { funcho, erva- } \\
\text { doce }\end{array}$ & fo & Espasmo, gripe, depurativo & Decocção & $\mathrm{C}$ & 11,50 \\
\hline $\begin{array}{l}\text { Apocynaceae } \\
\text { Mandevilla velutina (Mart. ex Stadelm) } \\
\text { Woodson }\end{array}$ & batata infalive & $\mathrm{r}$ & $\begin{array}{l}\text { Doença de chaga, depurativo, } \\
\text { afecções renais, gastrite }\end{array}$ & $\begin{array}{l}\text { Decocção, } \\
\text { vinho } \\
\text { medicinal }\end{array}$ & $\mathrm{C}$ & 23,00 \\
\hline Hancornia speciosa Gomes & mangaba & fr,fo & Câncer & Decocção & $\mathrm{C}$ & 7,69 \\
\hline Himatanthus drasticus (Mar.) Plumel. & tibornia & fo & Gripe, pneumonia, vermífugo & Decocção & $\mathrm{C}$ & 7,60 \\
\hline $\begin{array}{l}\text { Araceae } \\
\text { Anthurium affine Schott }\end{array}$ & salsa-paredão & $\mathrm{r}$ & Infecções uterinas & $\begin{array}{l}\text { Vinho } \\
\text { medicinal }\end{array}$ & $\mathrm{C}$ & 7,69 \\
\hline $\begin{array}{l}\text { Philodendron bipinnatifidum Schott \& } \\
\text { Endlicher }\end{array}$ & sipó-ímbe & fo & Contusão & Decocção & $\mathrm{C}$ & 7,69 \\
\hline $\begin{array}{l}\text { Arecaceae } \\
\text { Cocos nucifera } \mathrm{L} \text {. }\end{array}$ & $\operatorname{coco}$ & fr & Vermífugo & Doce & $\mathrm{C}$ & 7,69 \\
\hline $\begin{array}{l}\text { Aristolochiaceae } \\
\text { Aristolochia cymbifera Mart. \& Zucc. }\end{array}$ & jarrinha & $\mathrm{r}$ & Infecções uterinas & Decocção & $\mathrm{C}$ & 7,69 \\
\hline $\begin{array}{l}\text { Asteraceae } \\
\text { Ageratum conysoides L. }\end{array}$ & mentrasto, & fo & Indigestão, cólicas & $\begin{array}{l}\text { Decocção, } \\
\text { infusão }\end{array}$ & $\mathrm{N}$ & 39.00 \\
\hline Artemisia absinthium L. & losna & fo & Diarreia, analgésico & Decocção & $\mathrm{C}$ & 12,30 \\
\hline $\begin{array}{l}\text { Asteraceae } \\
\text { Artemisia vulgaris L. }\end{array}$ & $\begin{array}{l}\text { artemige, } \\
\text { artimige }\end{array}$ & fo & Infecções, indigestão & Infusão & $\mathrm{C}$ & 15,30 \\
\hline Baccharis trimera (Less.) DC. & carqueja & fo & Fígado, analgésico & Decocção & $\mathrm{C}$ & 23,00 \\
\hline Bidens Alba (L.) DC. & picão & fo & Icterícia, hepatite & Decocção & $\mathrm{N}$ & 32,00 \\
\hline Calendula officinalis L. & cravo & fo & Analgésica & Tintura & $\mathrm{C}$ & 7,69 \\
\hline Chamomilla recutita (L.) Rauschert & camomila & & Calmante, cólica & Infusão & $\mathrm{C}$ & 15,30 \\
\hline Lactuca sactuca L. & alface & fo, $\mathrm{r}$ & Calmante, reumatismo & Infusão, suco & $\mathrm{C}$ & 5,10 \\
\hline Mikania glomerata Spreng. & guaco & fo & $\begin{array}{l}\text { Expectorante, tosse, } \\
\text { febrífugo, depurativo }\end{array}$ & $\begin{array}{l}\text { Decocção, } \\
\text { maceração }\end{array}$ & $\mathrm{C}$ & 2,50 \\
\hline Solidago chilensis Meyen & arnica & fo & Contusão, gripe, analgésico & Banho, infusão & $\mathrm{C}$ & 26,30 \\
\hline Soliva pterosperma (Juss.) Less. & $\begin{array}{l}\text { marcelinha, } \\
\text { macela }\end{array}$ & fo & Diarreia, indigestão & $\begin{array}{l}\text { Decocção, } \\
\text { infusão, } \\
\text { macerado }\end{array}$ & $\mathrm{C}$ & 33,10 \\
\hline Tanacetum parthenium (L.) Sch. Bip. & $\begin{array}{l}\text { artimige, } \\
\text { margaridinha }\end{array}$ & fo, $f l$ & Indigestão, amenorreia & $\begin{array}{l}\text { Decocção, } \\
\text { infusão }\end{array}$ & $\mathrm{C}$ & 7,69 \\
\hline Vernomia condensata Baker & caferana & fo & Indigestão & Macerado & $\mathrm{C}$ & 38,40 \\
\hline Vernomia polyanthes Less. & assa-peixe & fo & Tosse, bronquite & Decocção & $\mathrm{N}$ & 15,30 \\
\hline
\end{tabular}




\begin{tabular}{|c|c|c|c|c|c|c|}
\hline Família/espécie & Nome vulgar & PU & Indicação & Preparo & $\mathrm{N} / \mathrm{C}$ & CUPc \\
\hline $\begin{array}{l}\text { Bignoniaceae } \\
\text { Arrabidaea brachypoda (DC.) Bur. }\end{array}$ & cervejinha & $\mathrm{r}$ & Infecções uterinas & $\begin{array}{l}\text { Vinho } \\
\text { medicinal, } \\
\text { decocção }\end{array}$ & $\mathrm{N}$ & 38,40 \\
\hline $\begin{array}{l}\text { Brassicaceae } \\
\text { Brassica oleracea DC. }\end{array}$ & couve & fo & Gota, laxante, visão & Suco & $\mathrm{C}$ & 2,50 \\
\hline $\begin{array}{l}\text { Bromeliaceae } \\
\text { Ananas comosus (L). Merr. }\end{array}$ & abacaxi & fr & Erisipela & Suco & $\mathrm{C}$ & 7,69 \\
\hline Bromelia antiacantha Bertol & gravatá & fr & Bronquite & Xarope & $\mathrm{N}$ & 7,69 \\
\hline $\begin{array}{l}\text { Caprifoliáceae } \\
\text { Sambucus nigra L. }\end{array}$ & sabugueiro & fo $\mathrm{fl}$ & Gripes & $\begin{array}{l}\text { Decocção, } \\
\text { infusão }\end{array}$ & $\mathrm{C}$ & 76,90 \\
\hline $\begin{array}{l}\text { Caricaceae } \\
\text { Carca papaya } \mathrm{L} .\end{array}$ & mamão & fo & Indigestão & Decocção & $\mathrm{C}$ & 23,00 \\
\hline $\begin{array}{l}\text { Caryocaraceae } \\
\text { Caryocar brasiliense Camb. }\end{array}$ & piqui & $\mathrm{c}$ & Infecção de garganta & Decocção & $\mathrm{N}$ & 7,69 \\
\hline $\begin{array}{l}\text { Cecropiaceae } \\
\text { Cecropia pachystachya Trécul }\end{array}$ & $\begin{array}{l}\text { imbaúba, } \\
\text { embaúba }\end{array}$ & fo & Afecções renais, bronquite & Decocção & $\mathrm{N}$ & 15,30 \\
\hline $\begin{array}{l}\text { Chenopodiaceae } \\
\text { Chenopodium ambrosioides } \mathrm{L} \text {. }\end{array}$ & $\begin{array}{l}\text { erva-de-santa- } \\
\text { maria }\end{array}$ & fo & Vermífugo, contusão, gripe & $\begin{array}{l}\text { Infusão, } \\
\text { decocção, } \\
\text { macerado }\end{array}$ & $\mathrm{N}$ & 44,70 \\
\hline $\begin{array}{l}\text { Cochlospermaceae } \\
\text { Cochlospermum regium (Mart. Ex. Schrank.) } \\
\text { Pilger }\end{array}$ & algodãozinho & r & Afecções uterinas & $\begin{array}{l}\text { Vinho } \\
\text { medicinal }\end{array}$ & $\mathrm{N}$ & 30,70 \\
\hline $\begin{array}{l}\text { Combretaceae } \\
\text { Terminalia argentea Mart. \& Zucc. }\end{array}$ & capitão & c & $\begin{array}{l}\text { Bronquite, pneumonia, tosse, } \\
\text { gripe }\end{array}$ & Decocção & $\mathrm{N}$ & 17,30 \\
\hline $\begin{array}{l}\text { Convolvulaceae } \\
\text { Operculina macrocarpa (Linn) Urb }\end{array}$ & ipú & $\mathrm{r}$ & Vermífugo & Pó & $\mathrm{N}$ & 30,70 \\
\hline $\begin{array}{l}\text { Crassulaceae } \\
\text { Sedum dendroideum Moc. \& } \\
\text { Sessé ex DC. }\end{array}$ & $\begin{array}{l}\text { bálsamo, } \\
\text { balsaminho }\end{array}$ & fo & $\begin{array}{l}\text { Dor de ouvido, queimação, } \\
\text { gastrite, sinusite, rinite }\end{array}$ & Macerado & $\mathrm{C}$ & 9,80 \\
\hline Bryophyllim pinnatum (Lam.) Oken & $\begin{array}{l}\text { folha-santa, } \\
\text { erva-santa }\end{array}$ & fo & Úlcera, gastrite & Xarope & $\mathrm{C}$ & 3,80 \\
\hline $\begin{array}{l}\text { Cucurbitaceae } \\
\text { Cucurbita pepo L. }\end{array}$ & abóbora & $\begin{array}{l}\text { sem, } \\
\text { fo }\end{array}$ & Vermífugo, indigestão & Paçoca, infusão & $\mathrm{C}$ & 7,60 \\
\hline Melothria sp. & candurão & $\mathrm{ca}$ & Afecções renais & Infusão & $\mathrm{C}$ & 7,69 \\
\hline Momordica charantia L. & $\begin{array}{l}\text { melão-de-são- } \\
\text { caetano, são- } \\
\text { caetano }\end{array}$ & fo & Bronquite, indigestão, fígado & Decocção & $\mathrm{N}$ & 20,50 \\
\hline Sechium edule (Jacq.) Sw & chuchu & fo & Pressão alta & Infusão & $\mathrm{C}$ & 7,69 \\
\hline $\begin{array}{l}\text { Dilleniaceae } \\
\text { Curatella americana } \mathrm{L} \text {. }\end{array}$ & lixeira & fo & Menopausa, vermífugo & Decocção & $\mathrm{N}$ & 23,00 \\
\hline $\begin{array}{l}\text { Euphorbiaceae } \\
\text { Croton antisiphiliticus Mart. }\end{array}$ & pé-de-perdiz & r & Infecções uterinas & $\begin{array}{l}\text { Vinho } \\
\text { medicinal, } \\
\text { decocção }\end{array}$ & $\mathrm{N}$ & 61,50 \\
\hline Croton urucurana Baill. & sangra-d'agua & sei & Cicatrizante, erisipela & Decocção & $\mathrm{N}$ & 15,30 \\
\hline Manihot esculenta Crantz. & mandioca & fo & Anemia & Pó & $\mathrm{C}$ & 7,69 \\
\hline Phyllanthus niruri L. & quebra-pedra & fo, $r$ & Afecções renais & Decocção & $\mathrm{N}$ & 38,40 \\
\hline Julocroton humilis Müll. Arg. & velame branco & sei, r & $\begin{array}{l}\text { Cicatrizante, purgante, } \\
\text { afecções renais, depurativo }\end{array}$ & $\begin{array}{c}\text { Decocção, } \\
\text { aplicação direta }\end{array}$ & $\mathrm{N}$ & 13,10 \\
\hline $\begin{array}{l}\text { Fabaceae } \\
\text { Amburana cearensis (Allemão) A. C. Sm }\end{array}$ & amburana & sem & Indigestão & Decocção & $\mathrm{C}$ & 7,69 \\
\hline Caesalpinia ferrea Mart & jucá & $\begin{array}{l}\text { sem, } \\
\mathrm{c}\end{array}$ & Analgésico, afecções renais & $\begin{array}{l}\text { Decocção, } \\
\text { vinho } \\
\text { medicinal }\end{array}$ & $\mathrm{C}$ & 30,7 \\
\hline Copaifera langsdorffii Desf. & $\begin{array}{l}\text { copaífera, } \\
\text { copaíba }\end{array}$ & sei & Acidente ofídico & Ingerir c/água & $\mathrm{N}$ & 7,69 \\
\hline
\end{tabular}




\begin{tabular}{|c|c|c|c|c|c|c|}
\hline Família/espécie & Nome vulgar & PU & Indicação & Preparo & $\mathrm{N} / \mathrm{C}$ & CUPc \\
\hline $\begin{array}{l}\text { Fabaceae } \\
\text { Dimorphandra gardneriana Tul. }\end{array}$ & faveira & sem & Estimulante & Decocção & $\mathrm{N}$ & 7,6 \\
\hline Dipteryx alata Vogel & baru & sem & Afrodisíaco & $\begin{array}{l}\text { Vinho } \\
\text { medicinal, } \\
\text { sementes } \\
\text { torradas }\end{array}$ & $\mathrm{N}$ & 15,3 \\
\hline Senna occidentalis ( L.) Link & fedegoso & $\mathrm{r}$ & Gripe & Decocção & $\mathrm{N}$ & 15,3 \\
\hline Pterodon emarginatus Vogel & sucupira & sem & Infecções de garganta & $\begin{array}{l}\text { Tintura, } \\
\text { decocção }\end{array}$ & $\mathrm{N}$ & 46,1 \\
\hline Hymenaea stigonocarpa Mart. & jatobá & fr & Afecções renais, próstata & $\begin{array}{l}\text { Decocção, } \\
\text { vinho } 1\end{array}$ & $\mathrm{~N}$ & 13,2 \\
\hline Tamarindus indica L. & tamarino & fr & Diurético, afecções renais & Suco & $\mathrm{C}$ & 3,8 \\
\hline $\begin{array}{l}\text { Iridaceae } \\
\text { Sisyrinchium vaginatum Spreng. }\end{array}$ & capim rei & $\mathrm{r}$ & Analgésico & Decocção & $\mathrm{N}$ & 7,69 \\
\hline $\begin{array}{l}\text { Lamiaceae } \\
\text { Lavandula angustifolia Mill. }\end{array}$ & alfazema & fo, fl & $\begin{array}{l}\text { Labirintite, indigestão, } \\
\text { analgésico, sinusite }\end{array}$ & Infusão & $\mathrm{C}$ & 1,92 \\
\hline Leonurus sibiricus L. & rubim, marroio & fo & Gripe, antiemético & Infusão & $\mathrm{N}$ & 15,30 \\
\hline Marsypianthes chamaedrys (Val) & hortelã & fo & $\begin{array}{c}\text { Gripe, vermífugo, infecção } \\
\text { de garganta }\end{array}$ & Decocção & $\mathrm{C}$ & 20,50 \\
\hline Mentha arvensis $\mathrm{L}$. & vique, hortelã & fo & Gripe & Infusão & $\mathrm{C}$ & 15,30 \\
\hline Mentha pulegium L. & poejo & fo & $\begin{array}{l}\text { Gripes, calmante, } \\
\text { expectorante }\end{array}$ & $\begin{array}{l}\text { Infusão, } \\
\text { decocção }\end{array}$ & $\mathrm{C}$ & 64,00 \\
\hline Mentha x piperita $\mathrm{L}$. & hortelã, alevante & fo & Gripe, diurético & Infusão & $\mathrm{C}$ & 41,10 \\
\hline Mentha $x$ villosa Huds & hortelã, menta & fo & Gripe & Infusão & $\mathrm{C}$ & 53,80 \\
\hline Ocimum basilicum $\mathrm{L}$. & manjericão & fo & Gripe & Infusão & $\mathrm{C}$ & 7,69 \\
\hline Ocimum gratissimum $\mathrm{L}$. & $\begin{array}{l}\text { alfavaca, } \\
\text { laçavenha }\end{array}$ & fo & Gripes, micose, diurético & $\begin{array}{l}\text { Decocção, } \\
\text { infusão }\end{array}$ & $\mathrm{C}$ & 38,50 \\
\hline Ocimum selloi Benth. & atroveram & fo & Emenagoga, cólica menstrual & Infusão & $\mathrm{C}$ & 7,60 \\
\hline Plectranthus barbatus Andrews & $\begin{array}{l}\text { boldo, falso- } \\
\text { boldo }\end{array}$ & fo & Indigestão & $\begin{array}{l}\text { Macerado, } \\
\text { infusão, } \\
\text { decocção }\end{array}$ & $\mathrm{C}$ & 100,00 \\
\hline Plectranthus amboinicus (Lour.) Spreng & hotelã pimenta & fo & Gripe, indigestão & $\begin{array}{l}\text { Decocção, } \\
\text { xarope }\end{array}$ & $\mathrm{C}$ & 46,10 \\
\hline Plectranthus neochilus Schlechter & anador & fo & Analgésico & $\begin{array}{l}\text { Maceração, } \\
\text { tintura }\end{array}$ & $\mathrm{C}$ & 15,30 \\
\hline Rosmarinus officinalis L. & alecrim & fo, $\mathrm{fl}$ & Gripe, depressão, analgésico & $\begin{array}{l}\text { Decocção, } \\
\text { infusão, tintura }\end{array}$ & $\mathrm{C}$ & 26,30 \\
\hline $\begin{array}{l}\text { Lauraceae } \\
\text { Persea americana Mill. }\end{array}$ & abacate & $\begin{array}{l}\text { sem, } \\
\text { fo, fl }\end{array}$ & $\begin{array}{c}\text { Afecções renais, reumatismo, } \\
\text { emenagoga, calvície }\end{array}$ & $\begin{array}{l}\text { Decocção, } \\
\text { infusão }\end{array}$ & $\mathrm{C}$ & 30,70 \\
\hline Cinnamomum zeylanicum Breyn. & canela & $c$, fo & Estimulante & $\begin{array}{l}\text { Decocção, } \\
\text { infusão }\end{array}$ & $\mathrm{C}$ & 7,69 \\
\hline $\begin{array}{l}\text { Liliaceae } \\
\text { Aloe vera (L.) Burm. F. }\end{array}$ & babosa & fo & Cicatrizante & Aplicação local & $\mathrm{C}$ & 30,70 \\
\hline Smilax japecanga Griseb. & japecanga & $\mathrm{r}$ & Diabetes & Decocção & $\mathrm{C}$ & 7,69 \\
\hline Herreria salsaparilha Mart. & salsaparrilha & $\mathrm{r}$ & Depurativo & Decocção & $\mathrm{N}$ & 23,00 \\
\hline $\begin{array}{l}\text { Loganiaceae } \\
\text { Strychnos pseudoquina A.St.- Hil. }\end{array}$ & quina & $\mathrm{c}$ & Diarreia & Decocção & $\mathrm{N}$ & 23,00 \\
\hline $\begin{array}{l}\text { Malpighiaceae } \\
\text { Malphighia glabra L. }\end{array}$ & acerola & fr & Gripe & Suco & $\mathrm{C}$ & 7,69 \\
\hline $\begin{array}{l}\text { Malvaceae } \\
\text { Abelmoschus esculentus (L.) Moench }\end{array}$ & quiabo & sem & Depurativo, anti-inflamatório & Decocção & $\mathrm{C}$ & 3,80 \\
\hline $\begin{array}{l}\text { Mimosoideae } \\
\text { Anadenanthera colubrina (Vell.) Brenan }\end{array}$ & angico & $\mathrm{c}$ & Gripe & Decocção & $\mathrm{N}$ & 7,69 \\
\hline
\end{tabular}




\begin{tabular}{|c|c|c|c|c|c|c|}
\hline Família/espécie & Nome vulgar & PU & Indicação & Preparo & $\mathbf{N} / \mathbf{C}$ & CUPc \\
\hline Stryphnodendron adstringens (Mart.) Coville & barbatimão & $\mathrm{c}$ & Cicatrizante, gastrite & $\begin{array}{l}\text { Decocção, pó, } \\
\text { banho }\end{array}$ & $\mathrm{N}$ & 56,60 \\
\hline $\begin{array}{l}\text { Moraceae } \\
\text { Morus nigra L. }\end{array}$ & amora & fo & $\begin{array}{l}\text { Menopausa, afecções } \\
\text { renais,febrífugo }\end{array}$ & Infusão & $\mathrm{C}$ & 20,50 \\
\hline Dorstenia asaroides Gardn. & carapiá & $\mathrm{r}$ & Sinusite & Pó & $\mathrm{N}$ & 15,30 \\
\hline Brosimum gaudichaudii Trécul & maminha-cadela & $\mathrm{c}$ & Afecções renais & Decocção & $\mathrm{N}$ & 7,69 \\
\hline $\begin{array}{l}\text { Myrtaceae } \\
\text { Syzygium aromaticum (L.) Merril. \& Perry }\end{array}$ & cravo da índia & bo-fl & Labirintite & Infusão & $\mathrm{C}$ & 7,60 \\
\hline Eucalyptus citriodora Hook. & eucalipto & fo & Gripe & Decocção & $\mathrm{C}$ & 15,30 \\
\hline Psidium guajava $\mathrm{L}$. & goiaba & fo & Diarreia & Infusão & $\mathrm{C}$ & 15,30 \\
\hline Syzygium cumini (L.) Skeels & jambolão & $\mathrm{c}$ & Diarreia & Decocção & $\mathrm{C}$ & 7,69 \\
\hline $\begin{array}{l}\text { Passifloraceae } \\
\text { Passiflora edulis Sims }\end{array}$ & maracujá & fo & Calmante, pressão alta & Infusão & $\mathrm{C}$ & 7,60 \\
\hline $\begin{array}{l}\text { Phytolaccaceae } \\
\text { Petiveria alliacea } \mathrm{L} \text {. }\end{array}$ & guiné, gambá & $\mathrm{r}$ & Reumatismo, analgésico & Decocção & $\mathrm{C}$ & 3,80 \\
\hline $\begin{array}{l}\text { Piperaceae } \\
\text { Pothomorphe umbellata (L.) Mig. }\end{array}$ & panaceia & fo & Afecções & Infusão & $\mathrm{C}$ & 7,69 \\
\hline $\begin{array}{l}\text { Plantaginaceae } \\
\text { Plantago major } \mathrm{L} .\end{array}$ & $\begin{array}{l}\text { tranchagem, } \\
\text { transagem }\end{array}$ & fo & Gripe, tosse, indigestão & Infusão & $\mathrm{N}$ & 24,60 \\
\hline $\begin{array}{l}\text { Poaceae } \\
\text { Cymbopogon citratus (DC) Stapf }\end{array}$ & capim cidreira & fo & $\begin{array}{l}\text { Gripe, expectorante, pressão } \\
\text { alta }\end{array}$ & Decocção & $\mathrm{C}$ & 71,50 \\
\hline Cynodon dactylon (L.) Pers & pé-de-galinha & $\mathrm{r}$ & Labirintite & Decocção & $\mathrm{N}$ & 7,69 \\
\hline Oryza sp. & arroz & sem & Erisipela & Pó & $\mathrm{C}$ & 7,69 \\
\hline Zea mays L. & milho & cami & Afecções renais & Decocção & $\mathrm{C}$ & 7,69 \\
\hline $\begin{array}{l}\text { Polygalaceae } \\
\text { Bredemeyera floribunda Willd. }\end{array}$ & $\begin{array}{l}\text { gargo-velho, } \\
\text { sabão-gentil, } \\
\text { pau-gemada }\end{array}$ & r & Depurativo & Gemada & $\mathrm{N}$ & 23,00 \\
\hline $\begin{array}{l}\text { Portulacaceae } \\
\text { Talinum paniculatum (Jacq.) Gaertn. }\end{array}$ & $\begin{array}{l}\text { ora-pro-nóbis- } \\
\text { miúdo }\end{array}$ & fo & Cicatrizante, emenagoga & $\begin{array}{l}\text { Infusão, } \\
\text { cataplasma }\end{array}$ & $\mathrm{N}$ & 3,84 \\
\hline $\begin{array}{l}\text { Punicaceae } \\
\text { Punica granatum } \mathrm{L} \text {. }\end{array}$ & romã & fr & Infecção de garganta & $\begin{array}{l}\text { Decocção, } \\
\text { tintura }\end{array}$ & $\mathrm{C}$ & 20,50 \\
\hline $\begin{array}{l}\text { Rosaceae } \\
\text { Pirus sp. }\end{array}$ & macieira & fr & Antiemético & Suco & $\mathrm{C}$ & 7,69 \\
\hline $\begin{array}{l}\text { Rubiaceae } \\
\text { Chiococca alba (L.) Hitchc. }\end{array}$ & caínca & $\mathrm{r}$ & Vermífugo & Pó & $\mathrm{N}$ & 30,80 \\
\hline Guettarda viburnoides Cham. \& Schlecht & veludo branco & $\mathrm{c}$ & Indigestão & Decocção & $\mathrm{N}$ & 7,69 \\
\hline Rudgea viburnoides (Cham.) Benth. & $\begin{array}{l}\text { congonha-de- } \\
\text { bugre }\end{array}$ & fo & Afecções renais, depurativo & Decocção & $\mathrm{N}$ & 7,60 \\
\hline $\begin{array}{l}\text { Rutaceae } \\
\text { Citrus aurantium L. }\end{array}$ & laranja & fl, fo & Gripes & Infusão & $\mathrm{C}$ & 38,40 \\
\hline Citrus limetta $\mathrm{R}$. & laranja lima & fr & Sinusite & Tintura & $\mathrm{C}$ & 7,69 \\
\hline Citrus medica $\mathrm{L}$. & cidra & $\mathrm{fl}$, fo & Gripe & Infusão & $\mathrm{C}$ & 7,69 \\
\hline Citrus sp. 1 & limão china & fo, fr & Gripe & Infusão & $\mathrm{C}$ & 7,69 \\
\hline Citrus sp. 2 & limão galego & fo, fr & Gripe, infecção de garganta & $\begin{array}{l}\text { Gargarejo, } \\
\text { infusão }\end{array}$ & $\mathrm{C}$ & 17,30 \\
\hline Coffea arabica $\mathrm{L}$. & café & fr & Analgésico, amenorreia & Infusão & $\mathrm{C}$ & 5,10 \\
\hline Ruta graveolens L. & arruda & fo & Conjuntivite, piolho & $\begin{array}{l}\text { Decocção, } \\
\text { macerado }\end{array}$ & $\mathrm{C}$ & 32,00 \\
\hline $\begin{array}{l}\text { Solanaceae } \\
\text { Datura stramonium L. }\end{array}$ & $\begin{array}{l}\text { trombeteira, } \\
\text { beladona }\end{array}$ & fo & Analgésico & Infusão & $\mathrm{C}$ & 7,69 \\
\hline Solanum lycocarpum St. Hil. & lobeira & $\mathrm{fl}$ & Gripes, bronquite & $\begin{array}{l}\text { Decocção, } \\
\text { xarope }\end{array}$ & $\mathrm{N}$ & 15,30 \\
\hline Solanum paniculatum L. & jurubeba & fo & Hepatite, fígado & Decocção & $\mathrm{C}$ & 7,60 \\
\hline
\end{tabular}




\begin{tabular}{|c|c|c|c|c|c|c|}
\hline Família/espécie & Nome vulgar & PU & Indicação & Preparo & $\mathrm{N} / \mathrm{C}$ & CUPc \\
\hline $\begin{array}{l}\text { Sterculiaceae } \\
\text { Guazuma ulmifolia Lam. }\end{array}$ & erva-lagarto & fo & Diarreia & Decocção & $\mathrm{N}$ & 7,69 \\
\hline $\begin{array}{l}\text { Verbenaceae } \\
\text { Lippia alba (Mill.) N. E. Br. }\end{array}$ & erva-cidreira & fo, $f l$ & $\begin{array}{c}\text { Pressão alta, gripe, calmante, } \\
\text { expectorante }\end{array}$ & $\begin{array}{c}\text { Infusão, } \\
\text { decocção, } \\
\text { xarope }\end{array}$ & $\mathrm{C}$ & 42,60 \\
\hline Stachytarpheta cayennensis (Rich.) Vahl & gervão & fo, $r$ & Contusão, gripe, infecções & $\begin{array}{l}\text { Macerado, } \\
\text { infusão }\end{array}$ & $\mathrm{N}$ & 44,00 \\
\hline $\begin{array}{l}\text { Vitaceae } \\
\text { Cissus verticillata (L.) Nicholson \& C.E. Jarvis }\end{array}$ & insulina & fo & Diabetes & Infusão & $\mathrm{C}$ & 7,69 \\
\hline $\begin{array}{l}\text { Vochysiaceae } \\
\text { Vochysia rufa Mart. }\end{array}$ & pau-doce & $\mathrm{c}$ & Diarreia & Decocção & $\mathrm{N}$ & 7,69 \\
\hline $\begin{array}{l}\text { Zingiberaceae } \\
\text { Costus spicatus (Jacq.) Sw. }\end{array}$ & cana-de macaco & $\begin{array}{l}\text { fo, } \\
\text { ca }\end{array}$ & Depurativa, diurético & Decocção & $\mathrm{N}$ & 15,3 \\
\hline Curcuma longa $\mathrm{L}$. & açafrão & ri & $\begin{array}{l}\text { Anti-inflamatório, gripe, } \\
\text { infecção de garganta }\end{array}$ & Pó & $\mathrm{C}$ & 7,60 \\
\hline Zingiber officinale Roscoe & $\begin{array}{l}\text { gengibre, } \\
\text { gingibre }\end{array}$ & ri & $\begin{array}{c}\text { Gripe, reumatismo, } \\
\text { colesterol, expectorante }\end{array}$ & Infusão & $\mathrm{C}$ & 34,20 \\
\hline
\end{tabular}

TABELA 2: Fator de Consenso dos Informantes sobre as plantas citadas pelos membros da comunidade de Santa Rita, Ituiutaba-MG. FCI: Fator de Consenso dos Informantes, DCC: Doença mais Citada na Categoria, NEC: Número de espécies citadas por categoria.

\begin{tabular}{lccc}
\hline \multicolumn{1}{c}{ Categorias } & FCI & DCC & NEC \\
\hline Distúrbio emocional (depressão) & 1 & Depressão & 3 \\
Menopausa & 0,83 & Menopausa & 7 \\
Cicatrizantes (lesões, feridas) & 0,82 & Cicatrizante & 18 \\
Doenças do aparelho respiratório (asma, bronquite, tosse, gripe, sinusite, & 0,69 & Gripe & 146 \\
pneumonia, expectorante) & 0,67 & Problemas do fígado & 10 \\
Doenças hepáticas (problemas do fígado, hepatite) & 0,66 & Indigestão & 61 \\
Doenças do aparelho digestivo (indigestão, gastrite, gases, vômitos, úlcera, & 0,64 & Vermifugo & 23 \\
queimação) & & Afecções renais & 61 \\
Doença parasitaria (vermifugo) & 0,60 & Reumatismo & 20 \\
Doenças do aparelho geniturinário (diurético, pedra nos rins, cólica mestrual, & Diarreia & 20 \\
afecções uterinas e renais, prostata) & 0,58 & Garganta & 23 \\
Doenças do sistema osteomuscular (artrose, reumatismo, torsão e contusão) & 0,58 & 0,45 & 17 \\
Anti-diarrêico (diarreia) & 0,44 & Depurativo do sangue \\
Infecções (garganta e outras) & 0,40 & Micose & 6 \\
Doenças do sangue e órgãos hematopoéticos (depurativo do sangue) & 0,33 & Calmante & 7 \\
Doenças de pele e do sistema tegumentar (micose, erisipélia, queda de cabelo) & 0,32 & Dor de cabeça & 23 \\
Efeito sedativo (calmante) & 0,17 & Emenagoga & 7 \\
Sintomas (dores não definidas, dor de cabeça, dor de ouvido, febres) & 0,5 & Laxante & 3 \\
Emenagoga & 0 & Hipertenção & 4 \\
Laxante & 0 & Diabetes & 3 \\
Doenças do aparelho circulatório (coração, hipertenção) & &
\end{tabular}


De acordo com o consenso dos informantes, a categoria com maior valor foi "distúrbio emocional" chegando ao valor máximo (1). Em seguida ficaram: menopausa $(0,83)$; cicatrizante $(0,82)$; doenças do aparelho respiratório $(0,69)$; doenças hepáticas $(0,67)$; doenças do aparelho digestivo $(0,66)$ e doença parasitaria $(0,64)$. As outras categorias tiveram valores inferiores a 0,60 (Tabela 2). Citações análogas para estas doenças também foram observadas por Amorozo e Gély (1988), Chisto et al. (2006) e Oliveira e Menini Neto (2012). Entretanto, para as categorias de doenças do aparelho respiratório e digestório, foram mencionados por Macedo et al. (2007), Costa e Mayworm (2011), Cunha e Bartolloto (2011) valores mais altos. Os valores obtidos indicam que as propriedades medicinais das espécies citadas para estas categorias merecem estudos mais aprofundados (MAIOLI-AZEVEDO; FONSECAKRUEL, 2007). Ainda, segundo Oliveira et al. (2010), pode se afirmar que as espécies agregadas nessas categorias são culturalmente as mais importantes para a comunidade uma vez que consisti em uma alternativa de cura (CUNHA; BARTOLLOTO, 2011).

Considerando os resultados obtidos, constatou-se que a utilização das plantas nativas foi 33,3\% menor em relação as cultivadas, o que pode demonstrar a perda da biodiversidade do Cerrado nesta região, fato reportado pelos entrevistados onde muitas espécies nativas utilizadas por eles não são mais encontradas devido, às roçadas nas pastagens e os frequentes desmatamentos oriundo das ações humanas. Entretanto, os resultados da CUPc mostram que 5,5\% das plantas citadas são amplamente utilizadas pela comunidade, o que ressalta a importância relativa destas espécies para os entrevistados. Ainda, de acordo com o Fator de Consenso dos Informantes, as categorias com valores altos concentram espécies importantes culturalmente para a comunidade.

Desse modo, é sugerida a realização de mais estudos que cataloguem o conhecimento associado ao uso das plantas medicinais em comunidades rurais, especialmente em biomas ameaçados como o Cerrado, visto que o resgate desse conhecimento pode propiciar elementos fundamentais para a conservação da biodiversidade, alternativas de subsistência e mesmo para a manutenção da diversidade cultural. Além disso, estudos químicos e farmacológicos devem ser realizados para a comprovação dos efeitos medicinais das espécies utilizadas como medicinal ocorrentes no Cerrado.

\section{Referências}

ALBUQUERQUE, U. P. Manejo tradicional de plantas em regiões neotropicais. Acta Botânica Brasilica, Feira de Santana, v. 13, n. 3, p. 307-315, 1999.

ALBUQUERQUE, U. P. Introdução a etnobotânica. 2. ed. Rio de Janeiro: Interciência, 2005. 93 p

ALBUQUERQUE, U. P.; HANAZAKI, N. As pesquisas etnodirigidas na descoberta de novos fármacos de interesse médico e farmacêutico: fragilidades e perspectivas. Revista Brasileira de Farmacologia, São Paulo, v. 16, p. 678-689, 2006.

ALVES, E. O.; MOTA, H. J.; SOARES, T. S.; VIEIRAM. C.; SILVA, C. B. Levantamento etnobotânico e caracterização de plantas medicinais em fragmentos florestais de Dourados-MS. Ciência Agrotécnica, Lavras, v. 32, n. 2, p. 651-658, 2008.

AMOROZO, M. C. M. Uso e diversidade de plantas medicinais em Santo Antonio do Leverger, MT, Brasil. Acta Botânica Brasilica, Feira de Santana, v. 16, n. 2, p. 189-203, 2002.

AMOROZO, M. C. M.; GÉLY, A. Uso de plantas medicinais por caboclos do baixo Amazonas. Barbacena, PA, Brasil. Boletim do Museu Paraense Emílio Goeldi, Série Botânica, Belém, v. 4, n. 1, p. 47-131, 1988.

BERLIN, A. B.; BERLIN, B. Some field methods in Medical Ethnobiology. Field Methods, Gainesville, v. 17, n. 3, p. 235-268, 2005.

BRASIL.AGÊNCIANACIONALDE VIGILÂNCIASANITÁRIA. Formulário de fitoterápicos da farmacopéia brasileira. Brasília: Anvisa, 2011. 126 p.

BRASIL. MINISTÉRIO DO MEIO AMBIENTE. MME. LEI № 11.428, de 22 de dezembro de 2006. Regulamenta a utilização e proteção da vegetação nativa do bioma Mata Atlântica. Decreto $\mathrm{n}^{\mathrm{o}}$ 6.660, de 21 de novembro de 2008. Disponível em: $<$ https://www. planalto.gov.br/ccivil_03/_ato2007-2010/2008/decreto/d6660. htm>. Acesso em: 10 jun. 2011.

BRASIL. MINISTÉRIO DA SAÚDE. CID - Classificação estatística internacional de doenças e problemas relacionados à saúde. 2008. Disponível em: <http://www.datasus.gov.br/cid10/ v2008/cid10.htm>. Acesso em: 10 mar. 2012.

CALIXTO, J. S.; RIBEIRO, E. M. O cerrado como fonte de plantas medicinais para uso dos moradores de comunidades tradicionais do alto Jequitinhonha, MG. In: ENCONTRO NACIONAL DE PÓS GRADUAÇÃO EM AMBIENTE E SOCIEDADE, 1, 2004, Indaiatuba. Anais eletrônicos. Indaiatuba: ANPPAS. Disponível em: <http://www.anppas.org.br/encontro_anual/ encontro2/GT/ GT02/GTJuliana.pdf>. Acesso em: 18 abr. 2011.

COSTA, V. P.; MAYWORM, M. A. S. Plantas medicinais utilizadas pela comunidade do bairro dos Tenentes - município de Extrema, MG, Brasil. Revista Brasileira de Plantas Medicinais, Botucatu, v. 13, n. 3, p. 282-292, 2011.

CHRISTO, A. G.; GUEDES-BRUNI, R. R.; FONSECA-KRUEL, V. S. Uso de recursos vegetais em comunidades rurais limítrofes à 
reserva biológica de Poço das Antas, Silva Jardim, Rio de Janeiro: Estudo de caso na gleba Aldeia Velha. Rodriguésia, Rio de Janeiro, v. 57, n. 3, p. 519-542, 2006.

CUNHA, S. A.; BORTOLOTTO, I. M. Etnobotânica de plantas medicinais no assentamento Monjolinho, município de Anastácio, Mato Grosso do Sul, Brasil. Acta Botanica Brasilica, Feira de Santana, v. 25, n. 3, p. 685-698, 2011.

DI STASI, L. C. O que faz uma planta medicinal funcionar. In: DI STASI, L. C. (Ed.). Plantas medicinais verdades e mentiras: o que os usuários e os profissionais de saúde precisam saber. São Paulo: UNESP, 2007a. p. 37- 44.

DI STASI, L. C. Plantas medicinais em seus distintos contextos de uso. In: DI STASI, L. C. (Ed.). Plantas medicinais verdades e mentiras: o que os usuários e os profissionais de saúde precisam saber. São Paulo: UNESP, 2007b. p. 45-70.

DI STASi, L. C.; GUIMARÃeS, E. M.; SANTOS, C. M.; HIRUMA-LIMA, C. A. Lamiales medicinais. In: DI STASI, L. C.; HIRUMA-LIMA, C. A. (Ed.). Plantas medicinais na Amazônia e na Mata Atlântica. 2. ed. São Paulo: UNESP, 2002. p. 406-448.

GIRALDI, M.; HANAZAKI, N. Uso e conhecimento tradicional de plantas medicinais no Sertão do Ribeirão, Florianópolis, SC, Brasil. Acta Botânica Brasilica, Feira de Santana, v. 24, n. 2, p. 395-406, 2010 .

HOSTEtTManN, K.; QUEIROZ, E. F.; VIEIRA, P. C. Principio ativo de superiores. São Carlos: EdUFscar, 2003. 152 p.

JUDD, W. S.; CAMPBELL, C. S.; KELLOGG, E. A.; STEVENS, P. F.; DONOGHUE, M. J. Relações filogenéticas das Angiospermas. In: JUDD, W. S.; CAMPBELL, C. S.; KELlOGG, E. A.; STEVENS, P. F.; DONOGHUE, M. J. (Ed.). Sistemática vegetal: um enfoque filogenético. 3. ed. Porto Alegre: Artmed, 2009. p. 225508.

LORENZI, H. Árvores brasileiras: manual de identificação e cultivo de plantas arbóreas do Brasil. 2. ed. Nova Odessa: Instituto Plantarum, 1998. $452 \mathrm{p}$.

LORENZI, H.; MATOS, F. J. A. Plantas medicinais no Brasil: nativas e exóticas. Nova Odessa: Instituto Plantarum, 2002. 544 p.

MACEDO, A. F.; OSHIIWA, M.; GUARIDO, C. F. Ocorrencia do uso de planyas medicinais por moradores de um bairro do municipio de Marilia-SP. Revista de Ciência e Farmacêutica Básica e Aplicada, São Paulo, v. 28, n. 1, p. 123-128, 2007.

MACIEL, M. A.; PINTO, A. C.; VEIGA, V. F. J.; GRYNBERG, N. F.; ECHEVARRIA, A. Plantas medicinais: a necessidade de estudos multidisciplinares. Química Nova, São Paulo, v. 25, n. 3, p. 429438, 2002.

MAIOLI-AZEVEDO, V.; FONSECA-KRUEL, V. S. Plantas medicinais e ritualísticas vendidas em feiras livres no Município do Rio de Janeiro, RJ, Brasil: estudo de caso nas zonas Norte e Sul. Acta Botanica Brasilica, Feira de Santana, v. 21, n. 2, p. 263-275, 2007.
MARONI, B. C.; DI STASI, L. C.; MACHADO, S. R. Plantas medicinais do cerrado de Botucatu. São Paulo: Unesp, 2006. 194 p. OLIVEIRA, F. C. S.; BARROS, R. F. M.; MOITA NETO, J. M. Plantas medicinais utilizadas em comunidades rurais de Oeiras, semiárido piauiense. Revista Brasileira de Plantas Medicinais, Botucatu, v. 13, n. 3, p. 282-292, 2010.

OLIVEIRA, E. R. I.; MENINI NETO, L. Levantamento etnobotânico de plantas medicinais utilizadas pelos moradores do povoado de Manejo, Lima Duarte - MG. Revista Brasileira de Plantas Medicinais, Botucatu, v. 14, n. 2, 2012. Disponível em: $<$ http://dx.doi.org/10.1590/S1516-05722012000200010>.

PASA, M. C. Saber local e medicina popular: a etnobotânica em Cuiabá, Mato Grosso, Brasil. Boletim do Museu Paraense Emílio Goeldi, Ciências Humanas, Belém, v. 6, n. 1, p. 179-196, 2011.

PILlA, M. A. C.; AMOROZO, M. C.; FURLAN, A. 2006. Obtenção e uso das plantas medicinais no distrito de Martim Francisco, município de Mogi-Mirim, SP, Brasil. Acta Botanica Brasilica, Feira de Santana, v. 20, n. 4, p. 789-802, 2006.

PINTO, E. P. P.;AMOROZO, M. C. M.; FURLAN, A. Conhecimento popular sobre plantas medicinais em comunidades rurais de Mata Atlântica - Itacaré, BA, Brasil. Acta Botanica Brasilica, Feira de Santana, v. 20, n. 4, p. 751-762, 2006.

PREFEITURA MUNICIPAL DE ITUIUTABA. Dados dobre o município. 2012. Disponível em $<$ http://www.prefeituradeituiutaba. gov.br/?menu=cidade $>$. Acesso em: 14 março 2012.

RAGUPATHY, S.; STEVEN, N. G.; MARUTHAKKUTTI, M.; VELUSAMY, B.; UL-HUDA, M. M.; Consensus of the 'Malasars' traditional aboriginal knowledge of medicinal plants in the Velliangiri holy hills, India. Journal of Ethnobiology and Ethnomedicine, London, v. 4, n. 8, 2008.

SILVA, R. B. L. A etnobotânica de plantas medicinais da comunidade quilombola de Curiaú, Macapá-AP, Brasil. 2002. 172 f. Dissertação (Mestrado em Agronomia) - Universidade Federal Rural da Amazônia, Belém. 2002.

SOUZA, V. C.; LORENZI, H. Botânica sistemática: guia ilustrado para identificação das famílias de Angiospermas da flora brasileira, baseado em APG II. Nova Odessa: Instituto Plantarum, 2005. 640 p.

SOUZA, V. C.; LORENZI, H. Botânica sistemática: guia ilustrado para identificação das famílias de Angiospermas da flora brasileira, baseado em APG II. 2. ed. Nova Odessa: Instituto Plantarum, 2008. $640 \mathrm{p}$.

TEIXEIRA, S. A.; MELO, J. I. M. Plantas medicinais utilizadas no município de Jupi, Pernambuco, Porto Alegre, Brasil. Iheringia, Série Botânica, Porto Alegre, v. 61, n. 1-2, p. 5-11, 2006.

VENDRUSCOLO, G. S.; MENTZ, L. A. Estudo da concordância das citações de uso e importância das espécies e famílias utilizadas como medicinais pela comunidade do bairro Ponta Grossa, Porto Alegre, RS, Brasil. Acta Botanica Brasilica, Feira de Santana, v. 20, n. 2, p. 367-382, 2006. 